\title{
How Individual Technology Propensities and Organizational Culture Influence B2B Customer's Behavioral Intention to Use Digital Services at Work?
}

\author{
Heli Hallikainen \\ University of \\ Eastern Finland \\ heli.hallikainen@ \\ $\underline{\text { uef.fi }}$
}

\author{
Bert Paesbrugghe \\ Vlerick Business \\ School \\ bert.paesbrugghe \\ @ vlerick.com
}

\author{
Tommi \\ Laukkanen \\ University of \\ Eastern Finland \\ tommi.laukkanen \\ @uef.fi
}

\author{
Deva Rangarajan \\ Vlerick Business \\ School \\ deva.rangarajan@ \\ vlerick.com
}

\author{
Mika Gabrielsson \\ University of \\ Eastern Finland \\ mika.gabrielsson \\ @uef.fi
}

\begin{abstract}
This study examines how individuals' technology readiness in conjunction with organizational culture impacts on B2B customers' behavioral intention toward using digital services in their procurement processes. We test our hypotheses with 755 B2B customers of a large Finnish supplier of furniture and interior solutions. We find that the propensity of individuals towards the use of technology, measured by the technology readiness of the buyers, has a significant effect on the behavioral intention toward using digital services at work. In addition, the customer organization's strategic emphasis - cost containment and revenue enhancement - have significant effects, while coping resources - task control and organizational support - do not affect the buyers' behavioral intention to use digital services in their procurement processes.
\end{abstract}

\section{Introduction}

Productivity pressures are driving business-tobusiness (B2B) customers to streamline their purchasing processes, and consequently, companies increasingly encourage their buyers to rely on digital technologies [34]. At the same time, supplier organizations are investing an ever-increasing share of their marketing budgets in developing digital services, but remain surprisingly fragmented in understanding the actual factors that drive their business customers to use these digital services. Given the increasing digital expenditures by the supplier companies, it is crucial for them to better understand the extent to which these services are likely to yield benefits, and the first step in this direction would involve understanding the extent to which these digital services are used by customers, and the factors that shape the attitudes and behaviors of these B2B customers. As this digital evolution is very likely to continue to disrupt the world of professional customers [23], it is key to identify and examine the factors that contribute to the use of digital services in B2B purchasing processes. In an attempt to better manage customer relationships, Verhoef, Lemon and Parasuraman [35] reason that firms turn to technology driven initiatives whose successful implementation depends on the alignment of the organization's structures and processes.

Our research contributes to the existing literature by focusing on the propensity of individual representatives of a B2B company to use technology, and factors of organizational culture which better help to understand what predicts B2B buyers' behavioral intentions regarding the use of digital services in their procurement processes. We find it striking that earlier research has mainly focused on either individual or organizational level factors when dealing with the usage of digital services. Thus we suggest that the more holistic dual perspective of our study could explain some of the contradictory results of the earlier literature. With regard to individuals and their propensity toward using technology, we refer to the recently renewed and streamlined Technology Readiness Index 2.0 [26], while the culture of the B2B buyer's organization refers to the organization's strategic emphasis regarding cost containment and revenue enhancement [38], and to coping resources that can be divided into the employee's possibility to have control over work tasks and to the socioemotional support of his/her organization [30].

The paper continues as follows. The next section reviews the theoretical background and shows our reasoning for the conceptual framework and hypotheses 
of the study. Thereafter, we describe the data and methods in Section 3 and validate the measurement constructs in Section 4. We present the results, including the data analysis and the hypotheses testing in Section 5. Finally, we draw conclusions with implications in Section 6, and discuss limitations and suggest future research avenues in Section 7.

\section{Literature review and hypotheses development}

\subsection{Behavioral intention}

Intention is a mental state representing a commitment to future actions. Individual behavior is stimulated by an imbalance between the present condition and some desired state. A belief links an object to a certain attribute [10], for example, that a certain action will assist in achieving the desired state. Intention, in turn, is the component that links desire and belief to action [20]. Thus, as Malle and Knobe [20] argue, an intentional action is a function required to accomplish the desired state and is based on an idea that a course of action will satisfy the desire. Consequently, behavioral intention is an indication of a person's readiness to perform a given behavior and it is considered to be the immediate antecedent of actual behavior [2].

Even though behavioral intention as a surrogate for customers' actualized usage behavior has recently been challenged [37], intention-behavior correlations as high as 0.90 [16] and 0.96 [31] have been reported, although in most cases, predictive accuracy is more modest [1]. In the current research we operationalize behavioral intention as the best available indicator of B2B customers' future use of digital services. With digital services we refer to the wide variety of digital technologies, services and tools (e.g. company websites, social media, mobile applications to mention a few) available for $\mathrm{B} 2 \mathrm{~B}$ buyers to assist purchasing process and decision-making.

\subsection{Technology readiness}

Prior research suggests that an individual's personal propensities impact the use of technology $[6,21,26]$. Even though companies commonly instruct and sometimes even mandate the way professionals use technology in organizational settings, an individual's personal orientation toward technology also impacts the way professionals use technology to carry out work related tasks, including business purchasing. We adopt the recently revised Technology Readiness Index 2.0 to assess individuals' personal orientations toward technology [26]. The Technology Readiness Index describes an individual's propensity to embrace and use new technologies for accomplishing goals in home life and at work [25,26]. Parasuraman [25] introduced a 36item technology readiness index (TRI) scale consisting of four dimensions: optimism, innovativeness, insecurity and discomfort. Recently the scale was revised to TRI 2.0 consisting of 16 items on a scale wherein optimism and innovativeness are motivators of technology use, and discomfort and insecurity are inhibitors of technology use [26]. An individual may simultaneously undergo both motivating and inhibiting feelings toward technology, and technology readiness describes the overall readiness of an individual to embrace technology [25].

The optimism dimension describes a generally positive view of technology, and a belief that technology offers individuals increased control, flexibility and efficiency in their lives, while innovativeness describes a tendency to be a pioneer and thought leader in adopting new technologies [26]. Discomfort reflects a perception of being overwhelmed by technology and lacking control over it [26]. Insecurity describes distrust toward technology that typically originates from having a general skepticism toward technology's ability to work properly and includes concerns about the potential harmful consequences of technology [26].

Prior research has linked technology readiness with behavioral intention $[9,17,18,19]$. However, these studies apply the original 36-item TRI 1.0 scale or its lightened scale, and thus the current research is among the first to utilize the revised TRI 2.0 scale. Consumer studies show that a customer's overall technology readiness is positively related with their intention to use e-services [18] and self-service technologies [19]. Lam, Chiang and Parasuraman [17] tested how the four dimensions of technology readiness influenced consumers' use of the Internet, and found that optimism and innovativeness positively influenced the personal use of the Internet, while the effect of insecurity was negative and the effect of discomfort was statistically not significant. Son and Han [32] focused on the effect of technology readiness on consumer's post adoption usage behavior, and found that consumers with high levels of optimism and innovativeness were likely to use innovative functions of technology more variously and frequently. In contrast, those who were highly ranked in the discomfort dimension were likely to employ basic functions more frequently [32].

We propose that technology readiness of individual B2B buyers will influence their behavioral intention to use digital services so that optimism and innovativeness will have a positive effect, while the effects of discomfort and insecurity will be negative. 
$H_{1}$ : Optimism positively influences B2B customers' behavioral intention to use B2B digital services.

$\mathrm{H}_{2}$ : Innovativeness positively influences $B 2 B$ customers' behavioral intention to use $B 2 B$ digital services.

$H_{3}$ : Discomfort negatively influences $B 2 B$ customers' behavioral intention to use B2B digital services.

$H_{4}$ : Insecurity negatively influences $B 2 B$ customers' behavioral intention to use B2B digital services.

\subsection{Organizational culture}

In addition to an individual buyer's personal propensity toward using technology, we propose that the organizational culture of the B2B customer organization influences the buyer's behavioral intention to use digital services. Thus, we include factors related to organizational culture measured on the individual level - namely the organization's strategic emphasis [38] and the coping resources of the employees [30] - in our conceptual model. Culture is a multifaceted and complex phenomenon, and can represent itself on multiple levels [27]. We acknowledge that our conceptualization of organizational culture is merely a facet of organizational culture and is measured as perceived by the customer participant.

2.3.1. Organization's strategic emphasis. In defining a company's strategic emphasis, we refer to Ye et al. [38] who developed two unit emphasis scales - revenue enhancement and cost containment - as possible anteceding constructs of frontline employees' productivity performance [29]. In the current research we focus on these strategic emphases in order to test their impact on the customer's behavioral intention to use digital B2B services. Verhoef et al. [35], for instance, suggests that a company's strategic intent impacts customer engagement.

Unit cost emphasis reflects the company's strategic emphasis on cost containment, and is related to the efficiency level of the company's processes. Examples of approaches that adopt a unit cost emphasis toward cost containment include Six Sigma and Total Quality Management [7,24]. Unit cost emphasis is rather internally oriented and focuses on the standardization of operations. Rust, Moorman, \& Dickson [29] note that successful cost efforts reduce the necessary labor and material input for a given output. Thus, these internal efficiency gains are indicative of measures to reduce cost.
Unit revenue emphasis refers to a company's revenue-generating strategy in order to respond to the company's evolving markets [38]. Companies that focus more on increasing revenues launch initiatives such as product innovations, improved customer service levels, or other attempts to augment customer satisfaction [29], despite the fact that the relationship between customer perceptions and financial results may be an indirect relationship [e.g. 12]. Measuring cost reductions is easier than calculating the impact of an improved level of customer satisfaction on the company's financial results. Rust, Moorman, \& Dickson [29], however, indicate that companies adopting a revenue emphasis strategy are likely to outperform companies characterized by a cost emphasis strategy or hybrid strategy consisting of both cost containment and revenue enhancement.

Davis, Bagozzi and Warshaw [5] posit that within organizational settings individuals form intentions toward behaviors which they believe will increase their job performance, regardless of the positive or negative feelings evoked toward the behavior per se. We test the influence of a B2B customer organization's cost containment and revenue enhancement strategies on their employees' behavioral intention by hypothesizing that:

$H_{5}$ : Unit cost emphasis positively influences the behavioral intentions of B2B customers toward using digital services.

$H_{6}$ : Unit revenue emphasis positively influences the behavioral intentions of $B 2 B$ customers toward using digital services.

2.3.2. Employee coping resources. An employee's coping resources - namely task control and organizational support - are means for employees to self-regulate and limit the dysfunctional effects of stress on their work-performance and well-being [30]. Coping resources refer to an employee's individual perception of having authority over work-related tasks, and of being supported by the company [30].

Task control $[4,13]$ measures the employee's autonomy and sense of empowerment in job-related tasks [30] and thus refers to the level of selfdetermination in performing those tasks [15]. Having autonomy over work-related tasks stimulates the employee's interest and involvement in performing the task, and leads to a higher level of task determination [15]. Results by Ke, Tan, Sia and Wei [14] show that when employees perceive a high level of autonomy over the tasks they perform, they are more motivated to explore information systems [14]. 
Organizational support captures the level of socioemotional support perceived by the employee [30]. Eisenberger, Fasolo and Davis-LaMaestro [8, p. 52] define organizational support as the extent to which employees perceive that the organization values their contribution and cares about their well-being. Mitchell, Gagné, Beandry and Dyer [22] find that organizational support perceived by the employee relates to the motivation to use new information technologies, together with behavioral and attitudinal reactions to new technologies.
Following prior research, we hypothesize that:

$H_{7}$ : Task control positively influences the behavioral intentions of B2B customers toward using digital services.

$H_{8}$ : Organizational support positively influences the behavioral intentions of $B 2 B$ customers toward using digital services.
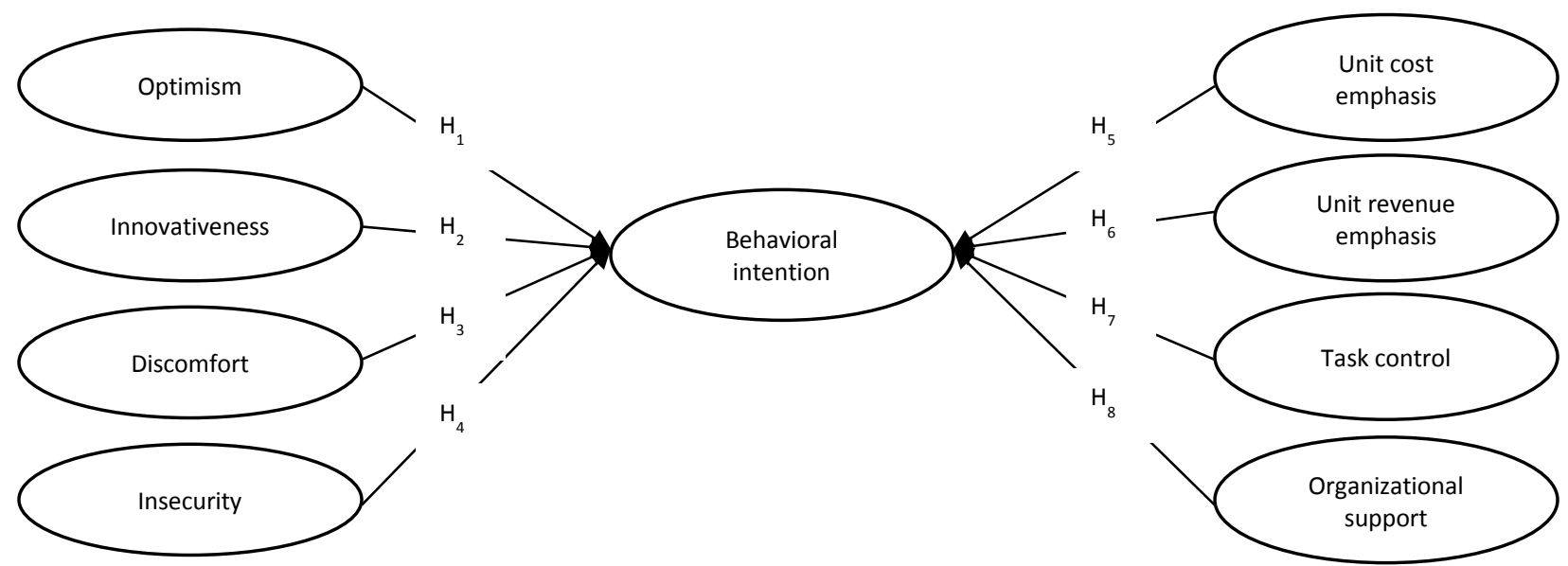

Figure 1. Conceptual model and hypotheses.

\section{Data and methods}

We collected the data for the research in autumn 2015 from the B2B customers of a large Finnish supplier of furniture and interior solutions. The sample consists of business decision makers who have an existing customer relationship with the specific company. In the data collection we targeted individuals who had a role in purchase related decision-making in their own organization. We first developed the questionnaire in English and thereafter translated it into Finnish using a professional translation company. The contact information of the customers was obtained from the cooperating supplier company, and an email with a link to the questionnaire was sent to 8,541 customers of the company. During a 40 day period a total of 763 responses were received (response rate 9\%), of which 755 were utilized for this study.

58 percent of the sample were females, and 42 percent were males. The age distribution in the sample ranges between 18 and 75 years $(\mathrm{M}=53.172 ; \mathrm{SD}=8.08)$. The respondents represent a wide range of industries (e.g. manufacturing, construction, wholesale and retail trade, information and communication, health, administrative and support services, public administration etc.).

For the purpose of the study, we adopted 9 constructs and 34 measurement items from the prior research. Firstly, the propensity individuals had toward technologies was measured using the indicators of technology readiness adopted from Parasuraman and Colby [26]. The Technology Readiness Index 2.0 is a 16-item measurement instrument measuring an individual's personal propensity toward adopting and using new technology in personal and work life [26]. This instrument focuses on four dimensions of technology readiness: optimism, innovativeness, insecurity, and discomfort, all consisting of four measurement items each [26]. Secondly, we examined organizational culture by measuring four constructs: unit cost emphasis, unit revenue emphasis, task control and organizational support $[30,38]$. Five indicators of unit cost emphasis and unit revenue emphasis were each derived from Ye, Marinova and Singh [38]. We measured task control with five indicators and organizational support with three indicators adopted from Singh [30]. All the organizational level variables were measured as individual perceptions of the participants about the particular construct. Thirdly, with 
regard to the dependent variable in our conceptual model, three measurement items of behavioral intention toward using digital services were adopted from Venkatesh and Bala [33]. A five-point Likert scale ranging from strongly disagree $=1$ to strongly agree $=5$ was used for all the constructs.

We tested non-response bias by comparing the responses of early and late respondents [3]. Early respondents represented the first quarter and late respondents the fourth quarter of the respondents in response order. The results showed that the early and late respondents differed from each other $(\mathrm{p}<0.05)$ only with respect to one measure item in innovativeness, unit cost emphasis, and unit revenue emphasis. Given that the study contains 34 measurement items, we conclude that non-response bias was not an issue in this study.

Before running the analysis, we recoded reverse coded items for task control and organizational support. Following prior research, we controlled for the effects of gender and age on the dependent variable in the analysis.

\section{Construct validation}

Even though the measures for our study derived from the prior research, we tested the validity of the theory-driven observed variables and constructs in the given context and sample. In order to validate the measurement instruments and to define the relations between observed and unobserved variables, we created a measurement model in Amos 21.0 with 9 latent constructs and 34 observed variables. The measurement model showed a good fit with $\chi^{2}=1243.495(\mathrm{df}=593$; $\mathrm{p}<0.001), \mathrm{CFI}=0.938$ and $\mathrm{RMSEA}=0.038$.

We also tested the discriminant validity of our constructs. Following Fornell and Larcker [11], the average variance extracted (AVE) for each construct was compared to the squared correlations between the constructs. The AVE values for discomfort and unit cost emphasis were below the squared CFA correlations for the other constructs. Hence, based on a low factor loading, we removed one indicator from discomfort. In addition, we removed one indicator from the unit cost emphasis and one indicator from the unit revenue emphasis due to high cross-item correlations (Appendix 1). After these modifications, discriminant validity was supported indicating that the remaining latent constructs are distinct from each other. The improved model shows a good fit with $\chi^{2}=954.574(\mathrm{df}=491 ; \mathrm{p}<0.001), \mathrm{CFI}=$ 0.951 and RMSEA $=0.035$. Composite reliability values all exceed 0.70 but some AVE values remained low (Table 1).

Table 1. Construct reliability, AVE values and squared between-construct correlations

\begin{tabular}{|c|c|c|c|c|c|c|c|c|c|c|}
\hline & CR & 1 & 2 & 3 & 4 & 5 & 6 & 7 & 8 & 9 \\
\hline 1.Optimism & 0.774 & 0.679 & & & & & & & & \\
\hline 2.Innovativeness & 0.849 & 0.512 & 0.766 & & & & & & & \\
\hline 3.Discomfort & 0.746 & -0.431 & -0.441 & 0.705 & & & & & & \\
\hline 4.Insecurity & 0.773 & -0.624 & -0.430 & 0.670 & 0.681 & & & & & \\
\hline 5.Unit cost emphasis & 0.746 & 0.305 & 0.238 & -0.156 & -0.216 & 0.654 & & & & \\
\hline 6.Unit revenue emphasis & 0.804 & 0.226 & 0.179 & -0.185 & -0.203 & 0.614 & 0.713 & & & \\
\hline 7.Task control & 0.791 & -0.218 & -0.135 & 0.241 & 0.207 & -0.152 & -0.347 & 0.660 & & \\
\hline 8.Organizational support & 0.872 & -0.096 & -0.028 & 0.190 & 0.213 & -0.072 & -0.289 & 0.640 & 0.834 & \\
\hline 9.Behavioral intention & 0.784 & 0.334 & 0.282 & -0.272 & -0.298 & 0.277 & 0.285 & -0.070 & -0.016 & 0.748 \\
\hline
\end{tabular}

Note: The AVE estimates are on the diagonals, the squared correlations of the constructs are below the diagonals.

\section{Results}

The results of the path analysis confirm that the propensity of an individual toward technology influences B2B customers' behavioral intention to use digital services. The results show that all technology readiness dimensions have a statistically significant effect on the customer's behavioral intention to use digital B2B services. Supporting the theory, optimism $(\beta=0.156 ; p<0.001)$ and innovativeness $(\beta=0.137$; $\mathrm{p}<0.01)$ positively influence behavioral intention while the effects of discomfort $(\beta=-0.121 ; \mathrm{p}<0.01)$ and insecurity $(\beta=-0.098 ; p<0.05)$ are negative. Hence, hypotheses $\mathrm{H} 1, \mathrm{H} 2, \mathrm{H} 3$ and $\mathrm{H} 4$ are supported.
With regard to organizational culture, unit cost emphasis $(\beta=0.088 ; p<0.05)$ and unit revenue emphasis $(\beta=0.195 ; p<0.001)$ positively influence the behavioral intention of B2B customers toward using digital services, giving support to hypotheses H5 and H6. The effects of task control and organizational support on behavioral intention are statistically not significant, rejecting hypotheses $\mathrm{H} 7$ and $\mathrm{H} 8$. The control variables gender and age - do not have statistically significant effects on the variation of the dependent variable. 


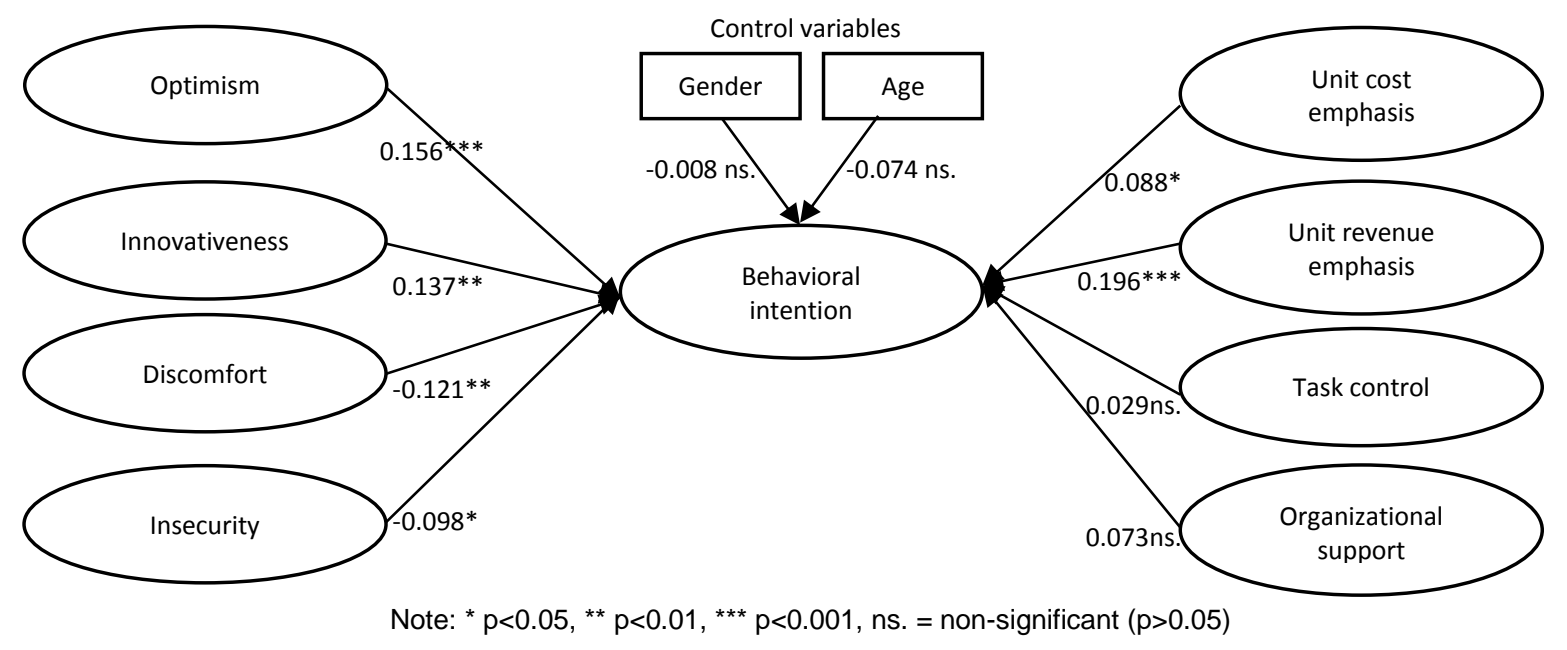

Figure 2. Results: standardized loadings

\section{Discussion and implications}

Our review of the academic literature highlights that very few empirical studies exist focusing on understanding the use of digital services among customers in B2B settings. The current research was set out to contribute to this gap in the literature.

Researchers have most typically assessed the adoption and use of digital services focusing on the characteristics those digital services possess, such as perceived ease of use and perceived usefulness. The characteristics and utilities of digital services are indeed important, but in the current study we chose an alternative approach focusing on individual propensities - harnessed in the form of a customer's readiness to adopt technology - and factors of organizational culture - harnessed in the form of the organization's strategic emphasis (i.e. unit cost emphasis and unit revenue emphasis) and the coping strategies of the employees (i.e. task control and organizational support). The approach of personal propensities and organizational culture is studied to a lesser extent compared to the research conducted on the perceived characteristics of digital technologies. We believe that in an organizational research context the personal propensity of an individual toward using technology together with context specific factors of organizational culture can help to form a more holistic view of the factors contributing to the use of digital technologies and services.

Examining individual personal propensities in explaining the use of digital technologies has recently received an increasing amount of interest in various research settings $[6,21,26,28]$. Our results indeed show that B2B customers' personality play a role in the behavioral intention of customer toward using digital services. The results of our study show that the four dimensions of technology readiness all have a statistically significant effect on the customer's behavioral intention to use digital B2B services. We find that optimism is the most influential dimension, followed by innovativeness, discomfort and insecurity, respectively. Lending support to the theory and prior studies conducted with the previous version of the Technology Readiness Index, version 1.0 $[17,25,26,36]$, optimism and innovativeness positively influence behavioral intention, while discomfort and insecurity have negative effects. The findings of our research indicate that users who display higher levels of optimism and innovativeness are likely to have a more favorable disposition toward using digital services. B2B companies aiming to encourage their customers to use digital technologies must do so by initially focusing on customers who possess the traits of optimism and innovativeness. Those individuals who are insecure or feel uncomfortable around new technology must not be forced to use new technologies lest they become demotivated. Forcing those B2B customers to use digital technologies might consequently lead to not just a decrease in their motivational levels, but might have an adverse impact on other employees around them who are more ambivalent toward new technologies.

The current study focuses on better understanding those factors that drive digital service use among B2B customers and for business purposes, and thus factors of organizational culture were also studied. Factors of organizational culture (i.e. unit cost emphasis, unit revenue emphasis, task control and organizational 
support) were included in our model to understand the use of digital services in the context of B2B procurement. Supplier companies spend money and effort on developing digital services for their customers, but clear evidence lacks as to whether these investments yield returns for the companies.

Out of the factors of organizational culture incorporated in our conceptual model, unit cost emphasis and unit revenue emphasis were found to have statistically significant effects on customers' behavioral intentions toward using digital services. Based on our results, a unit revenue emphasis, focusing on revenue enhancement, is the most influential on behavioral intention, followed by unit cost emphasis. This finding supports previous research [29] by showing that an organization's emphasis on revenue enhancement compared to cost containment, leads to a higher behavioral intention toward using digital services. On the other hand, customers may use digital services as a way of informing themselves, so that they can have a more enlightened conversation with their suppliers, or depending on the strategy of the company, adapt their requirements toward their suppliers. Thus, it is very important for supplier companies to understand the strategy of their customer companies and target specific messages tailored to these customers. Doing this will result in increased behavioral intentions of using digital services among customers.

The hypotheses about the effects of task control and organizational support were not supported by the results. One possible explanation could be that customers consider digital services only as an additional way of interacting with their suppliers, not necessarily having an impact on their job performance. Alternatively, there may be possible mediators between the coping resources (task control and

\section{References}

[1] I. Ajzen, C. Czasch and M.G. Flood, "From Intentions to Behavior: Implementation Intention, Commitment, and Conscientiousness", Journal of Applied Social Psychology, (39:6), 2009, pp. 1356-1372.

[2] I. Ajzen, "The theory of planned behaviour", Organizational behavior and human decision processes, (50:2), 1991, pp. 179-211.

[3] J.S. Armstrong \& T.S. Overton, "Estimating nonresponse bias in mail surveys", Journal of Marketing Research, (14:3), 1977, pp. 396-402.

[4] J.E. Bateson, "Self-service consumer: An exploratory study", Journal of retailing, 1985.

[5] F.D. Davis, R.P. Bagozzi and P.R. Warshaw, "User acceptance of computer technology: a comparison of two organizational support) and behavioral intention, which we have omitted in our model. However, further research must take into consideration the level of complexity involved for customers to start using digital services in addition to their day-to-day activities.

\section{Limitations and future research}

One of the main limitations of our research is that we, as is the case with a majority of other studies, use self-reported measures of behavioral intention instead of data about customers' actual usage behavior. Future research should take into consideration multiple sources of data to verify the relationships in our research model. Our research relied on cross-sectional data, which also has its limitations. Longitudinal research designs could be implemented to form a better understanding of how customers' attitudes toward digital services develop over time, and how behavioral intentions turn into actual behavior. This would shed useful light on the dynamic nature of the attitude formation process and its corresponding impact on the adoption of digital technologies and services in B2B buying. Incorporating additional factors from the technology acceptance model, e.g. perceived ease of use and perceived usefulness, might help future researchers to form an even more holistic view of the impacts of individual propensities toward using technology and factors of organizational culture on the intention to use digital technologies and services in B2B buying. In addition, future research should examine possible mediators between coping resources and the behavioral intention to use digital services, as our study posits that no direct effects exist.

theoretical models", Management science, (35:8), 1989, pp. 982-1003.

[6] S. Devaraj, R.F. Easley and J.M. Crant, "Research note How does personality matter? Relating the five-factor model to technology acceptance and use", Information Systems Research, (19:1), 2008, pp. 93-105.

[7] G.S. Easton and S.L. Jarrell, "The effects of Total Quality Management on corporate performance: An empirical investigation", The Journal of Business, (71:2), 1998, 253307.

[8] R. Eisenberger, P. Fasolo and V. Davis-LaMastro, "Perceived organizational support and employee diligence, commitment, and innovation", Journal of applied psychology, 75(1), 1990, pp. 51-59.

[9] N. Erdoğmuş and M. Esen, "An investigation of the effects of technology readiness on technology acceptance in e-HRM", Procedia-Social and Behavioral Sciences, 24, 2011, pp. 487-495. 
[10] M. Fishbein and I. Ajzen, "Belief, attitude, intention, and behavior: An introduction to theory and research", Reading, MA: Addison-Wesley, 1977.

[11] C. Fornell and F.D. Larcker, "Evaluating structural equation models with unobservable variables and measurement error", Journal of Marketing Research, (18:1), 1981, pp. 39-50.

[12] M.D. Johnson and A. Gustafsson, "Improving Customer, satisfaction, loyalty, and profit: An integrated measurement and management system", Jassey Bass, San Francisco, CA, 2000, pp. 83-87.

[13] R.A. Karasek Jr, "Job demands, job decision latitude, and mental strain: Implications for job redesign", Administrative science quarterly, (24:2), 1979, pp. 285-308. [14] W. Ke, C.H. Tan, C.L. Sia and K.K. Wei, "Inducing intrinsic motivation to explore the enterprise system: The supremacy of organizational levers", Journal of Management Information Systems, (29:3), 2012, pp. 257290.

[15] H.W. Kim, H.C. Chan and S. Gupta, "Examining information systems infusion from a user commitment perspective", Information Technology \& People, (29:1), 2016, pp. 173-199.

[16] G.W. King, (1975). "An analysis of attitudinal and normative variables as predictors of intentions and behaviour", Communications Monographs, (42:3),1975, pp. 237-244.

[17] S.Y. Lam, J. Chiang and A. Parasuraman, (2008), "The effects of the dimensions of technology readiness on technology acceptance: An empirical analysis", Journal of interactive marketing, (22:4), 2008, pp. 19-39.

[18] C.H. Lin, H.Y. Shih and P.J. Sher, "Integrating technology readiness into technology acceptance: The TRAM model", Psychology \& Marketing, (24:7), 2007, pp. 641-657.

[19] J.S.C. Lin and P.L. Hsieh, "The influence of technology readiness on satisfaction and behavioral intentions toward self-service technologies", Computers in Human Behavior, (23:3), 2007, pp. 1597-1615.

[20] B.F. Malle and J. Knobe, "The folk concept of intentionality", Journal of Experimental Social Psychology, (33:2), 1997, pp. 101-121.

[21] J.C. McElroy, A.R. Hendrickson, A.M. Townsend and S.M. DeMarie, "Dispositional factors in internet use: personality versus cognitive style", MIS quarterly, (31:4), 2007, pp. 809-820.

[22] J.I. Mitchell, M. Gagné, A. Beaudry and L. Dyer, "The role of perceived organizational support, distributive justice and motivation in reactions to new information technology", Computers in Human Behavior, (28:2), 2012, pp. 729-738. [23] A.L. Ostrom, M.J. Bitner, S.W. Brown, K.A, Burkhard, M. Goul, V. Smith-Daniels, D. Haluk. and E. Rabinovich, "Moving forward and making a difference: research priorities for the science of service", Journal of Service Research., (13:1), 2010, pp. 4-36.

[24] P. Pande, R. Neuman and R.R. Cavanagh, "The six sigma way: How GE, Motorola, and other top companies are honing their performance", McGraw Hill Professional, 2000.

[25] A. Parasuraman (2000), "Technology Readiness Index (TRI) a multiple-item scale to measure readiness to embrace new technologies", Journal of service research, (2:4), 2000, pp. 307-320.

[26] A. Parasuraman and C.L. Colby, "An updated and streamlined technology readiness index TRI 2.0", Journal of service research, (18:1), 2015, pp. 59-74.

[27] E. H. Schein, Organizational culture and leadership, Jossey-Bass, San Francisco, 2010.

[28] M. Ratchford and M. Barnhart, "Development and validation of the technology adoption propensity (TAP) index", Journal of Business Research, (65:8), 2012, pp. 1209-1215.

[29] R.T. Rust, C. Moorman and P.R. Dickson, "Getting return on quality: revenue expansion, cost reduction, or both?", Journal of marketing, (66:4), 2002, pp. 7-24.

[30] J. Singh, "Performance productivity and quality of frontline employees in service organizations", Journal of marketing, (64:2), 2000, pp. 15-34.

[31] J. G. Smetana and N.E. Adler, "Fishbein's Value x Expectancy Model An Examination of Some Assumptions", Personality and Social Psychology Bulletin, (6:1), 1980, pp. 89-96.

[32] M. Son and K. Han, "Beyond the technology adoption: Technology readiness effects on post-adoption behaviour", Journal of Business Research, (64:11), 2011, pp. 1178-1182. [33] V. Venkatesh and H. Bala, "Technology acceptance model 3 and a research agenda on interventions", Decision sciences, (39:2), 2008, pp. 273-315.

[34] W. Verbeke, B. Dietz and E. Verwaal, "Drivers of sales performance: A contemporary meta-analysis. Have salespeople become knowledge brokers?", Journal of the Academy of Marketing Science, (39:3), 2001, pp. 407-428. [35] P.C. Verhoef, K.N. Lemon, A. Parasuraman, A. Roggeveen, M. Tsiros and L.A. Schlesinger, "Customer experience creation: Determinants, dynamics and management strategies", Journal of retailing, (85:1), 2009, pp. 31-41.

[36] R. Walczuch, J. Lemmink, and S. Streukens, "The effect of service employees' technology readiness on technology acceptance". Information \& Management, (44:2), 2007, pp. 206-215.

[37] J. Wu and H. Du, "Toward a better understanding of behavioral intention and system usage constructs", European Journal of Information Systems, (21:6), 2012, pp. 680-698. [38] J. Ye, D. Marinova and J. Singh, "Strategic change implementation and performance loss in the front lines", Journal of Marketing, (71:4), 2007, pp. 156-171. 
Appendix 1. Measurement items and standardized estimates

\begin{tabular}{|c|c|c|}
\hline Construct & Measurement item & $\begin{array}{l}\text { Std. } \\
\text { loading }\end{array}$ \\
\hline \multirow[t]{4}{*}{ Optimism } & New technologies contribute to a better quality of life. & 0.726 \\
\hline & Technology gives me more freedom of mobility. & 0.652 \\
\hline & Technology gives people more control over their daily lives. & 0.637 \\
\hline & Technology makes me more productive in my personal life. & 0.700 \\
\hline \multirow[t]{3}{*}{ Innovativeness } & Other people come to me for advice on new technologies. & 0.758 \\
\hline & $\begin{array}{l}\text { In general, I am among the first in my circle of colleagues and friends to acquire new } \\
\text { technology when it appears. }\end{array}$ & 0.856 \\
\hline & $\begin{array}{l}\text { I can usually figure out new high-tech products and services without help from others. } \\
\text { I keep up with the latest technological developments in my areas of interest. }\end{array}$ & $\begin{array}{l}0.671 \\
0.768\end{array}$ \\
\hline \multirow[t]{4}{*}{ Discomfort } & $\begin{array}{l}\text { When I get technical support from a provider of a high-tech product or a service, } 1 \\
\text { sometimes feel as if I am being taken advantage of by someone who knows more than } \\
\text { tdo. }\end{array}$ & 0.535 \\
\hline & $\begin{array}{l}\text { Technical support lines are not helpful because they don't explain things in terms I } \\
\text { understand. }\end{array}$ & 0.652 \\
\hline & $\begin{array}{l}\text { Sometimes, I think that technology systems are not designed for use by ordinary } \\
\text { people. }\end{array}$ & 0.750 \\
\hline & $\begin{array}{l}\text { There is no such thing as a manual for a high-tech product or a service that's written in } \\
\text { plain language. }\end{array}$ & 0.707 \\
\hline \multirow[t]{4}{*}{ Insecurity } & People are too dependent on technology to do things for them. & 0.644 \\
\hline & Too much technology distracts people to a point that is harmful. & 0.787 \\
\hline & Technology lowers the quality of relationships by reducing personal interaction. & 0.717 \\
\hline & I do not feel confident doing business with a place that can only be reached online. & 0.552 \\
\hline \multirow{5}{*}{$\begin{array}{l}\text { Unit cost } \\
\text { emphasis }\end{array}$} & New digital services are regularly used to help reduce costs with suppliers. & 0.616 \\
\hline & Managers use supplier cost data to make changes in unit practices. & 0.632 \\
\hline & $\begin{array}{l}\text { We are asked to make our supervisors aware of cost implication of choosing each } \\
\text { supplier. }\end{array}$ & 0.616 \\
\hline & Training programs emphasize cost control in job-related decisions. & 0.673 \\
\hline & Strict cost control systems are in place for most of the things that we do. & 0.645 \\
\hline \multirow{5}{*}{$\begin{array}{l}\text { Unit revenue } \\
\text { emphasis }\end{array}$} & Managers implement initiatives that bring new source of revenue. & 0.629 \\
\hline & $\begin{array}{l}\text { New technologies are regularly adopted that allow our unit to offer new services to our } \\
\text { internal customers. }\end{array}$ & 0.648 \\
\hline & We are encouraged to provide ideas for expanding our services to internal customers. & 0.774 \\
\hline & We are appropriately recognized for developing new sources of revenue. & 0.707 \\
\hline & Our supervisors closely monitor the financial success of new initiatives. & 0.722 \\
\hline \multirow[t]{5}{*}{ Task control } & Having little control over the tasks I perform $(R)$ & 0.497 \\
\hline & Having little say in decisions that affect my work $(\mathrm{R})$. & 0.744 \\
\hline & Having no control over what is happening in my work area $(R)$. & 0.736 \\
\hline & Having little say in top management's decisions that affect me $(R)$. & 0.632 \\
\hline & Not having the authority to do what is required $(R)$. & 0.658 \\
\hline Organizational & Having an organization that doesn't recognize my contribution $(R)$. & 0.821 \\
\hline \multirow[t]{2}{*}{ support } & Having an organization that will not go to good lengths to support me $(R)$. & 0.937 \\
\hline & Having an organization that has several incompetencies $(R)$. & 0.732 \\
\hline Behavioral & Assuming I had access to the company's digital service, I intend to use it. & 0.834 \\
\hline \multirow[t]{2}{*}{ intention } & Given that I had access to the company's digital service, I predict that I would use it. & 0.859 \\
\hline & I plan to use the company's digital services in the next 3 months. & 0.496 \\
\hline
\end{tabular}

